\title{
El libro maligno: \\ Aura e Inez
}

\section{Margarita Rojas G.}

Universidad Nacional de Costa Rica

Aura, de Carlos Fuentes, es un relato acerca de la relación entre

- el tiempo y la lectura; quizás esto mismo explica la relación inversamente proporcional entre el tamaño del texto y la cantidad de intertextos apelados y la larga historia de interpretaciones. Después de cuarenta años, Instinto de Ine: (2001) del mismo autor reelabora algunos problemas presentes en Aura —el mundo de la magia, la situación comunicativa explícita del narrador-, y trata de responder a la pregunta sobre el tiempo planteada en el primer relato.

La lectura de Aura significa una progresiva acumulación de dudas respecto a la naturaleza de los acontecimientos narrados, las identidades de sus personajes, la coherencia de la narración: la lectura, en vez de asistir al progresivo descubrimiento de un mundo, pareciera enfrentarse a un oscuro designio de provocar mayor confusión. Muchos son los hechos que perturban al Lector y crean un efecto de ambigüedad; algunos parecen premoniciones y otros crean contradicciones entre los personajes; todos contribuyen a cuestionar la relación entre Saga, Consuelo y Aura y, sobre todo, a hacer dudar sobre el carácter real del mundo al que penetra Felipe.

La mayor inquietud quizá se presenta con la identidad del narrador. En este trabajo se tratará de demostrar que el acto de identificación de la voz narrativa se corresponde con la forma de la novela: la forma de la materia narrada coincide con la forma de la narración y la unión de ambas —el texto— remite a una concepción particular del 
Libro, del acto de la lectura y de la relación de ambos con el transcurso de la temporalidad.

\section{Las lecturas}

La mayoría de los numerosos trabajos de interpretación sobre Aura se han dedicado a estudiar el mundo representado, especialmente a tratar de establecer la identidad del narrador, la identidad de los personajes, y a esclarecer sus relaciones. Muchos ocasi todos articulan estos problemas con el mundo de la brujería, la hechicería, la magia, etc. '

En el artículo de E. Paiewonsky Conde se reseñan algunas interpretaciones sobre la identidad del narrador, en primer lugar, la del propio escritor, Carlos Fuentes, quien considera que el narrador es quienquiera que el lector desee. Para Paiewonsky, las soluciones sobre la identidad del narrador son varias: a. es Llorente; b. es la voz o la conciencia de la anciana, «esencia de lo femenino» y «artífice de la zona nocturna»; c. algún augur; d. Felipe que habla consigo mismo o su conciencia; e. el lector, porque la conciencia del lector es análoga a la de los personajes: el YO es un espejo que refleja la acción, es decir, el ojo del Lector, y porque el discurso del narrador transcurre en presente, que es el tiempo del Lector (152); f. finalmente, se trata de un enigma imposible de solucionar. Paiewonsky propone también que el narrador, «el cuarto punto elusivo», es el locus de articulación del discurso: tiene una perspectiva sin perspectiva, por esto es ambiguo ${ }^{2}$.

1. Aunque la lglesia las confunde $y$ las condena por igual. la brujería $y^{\prime}$ la magia no son lo mismo: la magia es un conocimiento «oficializado». mientras la brujería es una desviación popular. que recurre a la ignorancia o a un paganismo de «bajo nitel»: además. se opone formalmente a la religión y al orden establecido. es típicamente femenina y' se vincula con lo demoníaco. En latín 'sortiarius' significa «el que pronuncia o arroja una suerte de la que tiene el poder y la práctica de un pacto concluido con el Demonio". Roland V'illeneuve. Dictiomnaire du Diable' (1989. 2a. edición: Paris. Omnibus. 1998) 906-912.

2. Este estudioso considera que Felipe es un ser refle jado en la conciencia del YO, así como Aura se refleja en la conciencia bruja de Consuelo: por el automatismo (138) el narrador es «un espejo verbal de Felipe. lo refleja en la contemplación de su reflejo. su doble. su antítesis temporal» (145). Para el crítico. también. el YO no es Consuelo: el emisor es ía conciencia de ese contacto (aunque comparte con Consuelo el conocimiento de que Felipe es Llorente) (140). el YO tiene una "penetración abismal» del TÚ y de su destino (141). E. Paiewonsky Conde. "La numerología como principio estructurante en Aura de Fuentes» en Ana María Hernández (ed.). Interpretaciones a la obrade Carlos Fluentes (Madrid. Beramar. 1990) 137-154. 
Posteriormente, Eduardo Dublé ha planteado que el narrador es la «manifestación textual del poder creador y profético del lenguaje narrativo» ${ }^{3}$. Para B. Gibert, se trata al mismo tiempo de una novela de intriga y la transcripción de un sueño de Consuelo; por esta razón, en parte, sugiere que la voz narrativa es la de Consuelo y que en realidad sólo hay un personaje ${ }^{4}$. F. García Núñez considera que se trata de un «sujeto narrativo omnisciente», un narrador «imperioso y determinante», generador de la novela e «hipóstasis omnipresente y absolutamente creadora de Felipe y sus circunstancias, semejante a Dios o al Demonio» ${ }^{5}$.

Otros críticos se han dedicado más bien a analizar el problema narrativo, específicamente, el recurso de las distintas personas gramaticales, y este asunto se ha referido a la obra en general de Fuentes, alrededor de la cual varios han llamado la atención sobre la importancia del mundo de las palabras. Paul de Virgilio, entre otros, propone que La muerte de Artemio Cruz se debe leer en un nivel que trascienda la comunicación mimética del acto de conversación y que se debe descubrir otra identidad, es decir, que dentro de un mensaje puramente discursivo, la segunda persona gramatical del narrador plantea la existencia de otra realidad, la de la comunicación. En consecuencia, menciona Virgilio, el texto «no es únicamente la «representación» de un acontecimiento, sino también la inscripción del discurso [en términos de Emile Benveniste] que permite al acontecimiento ser

3. Eduardo Thomas Dublé. «Hechicerías del discurso narrativo latinoamericano: Aura de Carlos Fuentes". Actas de las VI Jornadas interdisciplinarias sobre religión y' cultura: "magia y religión" (Universidad de Chile. 1998). <http:// www.uchile.cl/facultades/ filosofia/publicaciones/cyber/cyber9/ethomas.ht>.

4. La «voz que impulsa a Felıpe Montero a moverse como una marioneta. que controla sus gestos y sus pensamientos. que conoce el principio y el fin de la historia, no puede ser otra que la voz de ia propia Consuelo Llorente (...) [Felipe] no es más que el falso protagonista de la novela (...) [él y Aura] han sido creados por la imaginación enfermiza de Consuelo como si realmente tuvicran vida. Ese proceso de creación unifica la forma y el contenido de la novela. de modo que están íntimamente relacionados». Berta Gibert Cardona, "El falso protagonista en Aura de Carlos Fuentes: notas para una nueva interpretación". Literarura de dosimundos. El encuentro) (Murcia. Colección Carabelas. 1993) 297-304.

5. «La poética narrativa de Carlos Fuentes». Bulletin hispanique, 94-1 (1992) 260. 
representado» ${ }^{6}$. En una perspectiva similar, C. Gómez Carro propuso que La región más transparente es «la región de las palabras, la única zona capaz de hacer comprensible, transparente, el mundo» ${ }^{7}$.

Como se verá más adelante, es útil recordar primero que la presencia elusiva de este narrador no es un rasgo constitutivo sino un efecto de la lectura: tras la segunda persona gramatical parece que hay alguien que se esconde, ese Otro encubierto pareciera que al mismo tiempo se muestra y se oculta, y que así constituye a aquel a quien se dirige y encubre al Yo que lo profiere. En segundo lugar, se sabe que, si bien el narrador puede relacionarse con su historia de distintas maneras y su existencia puede estar explícita o implícita, es siempre un elemento invariante de la situación narrativa ${ }^{8}$.

Aura empieza precisamente con una palabra que revela esa presencia inquietante y su contraparte, el Lector, pues, como ya se ha destacado ${ }^{9}$, esa primera palabra contiene una triple referencia a la lectura. «Lees» se dirige simultáneamente al Lector y al personaje, quien aparece en el acto de leer un diario: desde allí, por entre las letras impresas, empieza a atraerlo la voz que lo conducirá desde la parte moderna al centro histórico.

El ingreso a la casa de Consuelo se anuncia como el tránsito a un mundo anormal, que pertenece a otro tiempo. Antes de entrar en la vieja mansión, Felipe percibe, por ejemplo, que en ese sector de la ciudad no puede vivir nadie $y$, en el momento de franquear la puerta de

0. "The reader is compelled to read La muerte de Artumio Cruz not as the representation of a death but as the structure of the communication of such an event». Virgilio. Paul de. "La muerte de Artemio Criz: The Relationship between Innoration in the Role of the Personal Pronouns in the Narrative and Reader Expectancy's. en Revisia canadiense de estudios hispánicoss ( $\because-1$. 1980) 97 y 95.

7. Carlos Gómez Carro, “Carlos Fuentes, narrador (1954-1967)» en Óscar Mata (coordinador). En torno a la literatura mexicana (México: Universidad Autonoma Metropolitana [1989]) 111.

8. Gérard Genette, «Persona» en Figuras III (1972. edición en español: Lumen. 1989).

9. Paiew onsky considera que la primera palabra establece un triple contacto: como anuncio del periódico. entre Consuelo (autora del texto) y Felipe (lector): como novela, entre Autor y Lector: y como narración, entre narrador e interlocutor. 137. 
entrada, comienza a imaginar cosas, como que el perro de la manija le sonríe. En el instante de traspasar el umbral, el narrador dice que el joven mira «por última vez», aunque sin poderr etener una sola imagen del «mundo exterior indiferenciado» $(14)^{10}$. Si lo que deja atrás es una especie de caos, esa nueva realidad a la cual ahora penetra, aparentemente para no volver a salir, debería entonces ser lo opuesto: armonía, orden, estructura. Y en efecto así será, aunque a Felipe le parezca lo contrario: como esta novela es una metáfora del proceso de lectura y la casa es el libro, entrar a ese nuevo ámbito desconocido es sinónimo del inicio de la lectura - el libro como un territorio virgen, organizado con reglas nuevas que se deben ir aprendiendo conforme se avanza en el proceso-. Así, los desconciertos que causan la falta de electricidad, la presencia/ausencia de criados, los cubiertos en la mesa, etc., son las ambigüedades propias de todo texto; los pocos días que allí permanece es el tiempo que se tarda en leer un libro, la voz que habla, a Felipe y al lector, evidencia la relación dialógica constitutiva de todo proceso de lectura.

\section{La bruja}

Una mujer domina la escena de los acontecimientos: incluso desde antes de su aparición física, parece hablarle desde la lejanía, a través del anuncio del diario cuando, en el segundo día y, ante la duda de Felipe, propone un aumento de salario para convencerlo.

En la mayoría de los estudios sobre Aura se ha aceptado que Consuelo es una bruja, semejante a las que describe Jules Michelet ${ }^{11}$. Antes de referir los múltiples cruces entre el texto de Fuentes y el del historiador francés, se pueden resaltar varios rasgos propios del mundo de la brujería: las actividades de Consuelo, los nombres de los personajes y el vínculo entre la coneja y la magia. Etimológicamente 'aura'

10. Se cita a partir de la lla. edición (México: Ediciones Era. 1976).

11. Jules Micheiet. La sorrière - Résumes, en Histoire de Francé, Paul Vialla Neix (ed.), Onres. 'completes de Michele't. t. VII. Flammarion. 1978, pp. 89-97: una edición en español: La briuja (1862. 5a. ediciön económica: Barcelona. Luis Tasso Serra. s.f., 268 pp. La «Advertencia a la segunda edición» tiene fecha del lo. de diciembre de 1862). 
significa 'ave rapaz diurna de plumaje negro con visos verdes y pico de color carne', y también 'hálito que penetra y vive en la mujer poseída por un demonio' ${ }^{\prime 2}$. Llorente se refiere seguramente a Juan Antonio Llorente, inquisidor español ${ }^{13}$; Saga significa 'mujer adivina, bruja que hace encantamientos, hechizos' ${ }^{14}$ y los conejos son animales lunares, entre otras cosas, porque acompañan a Hécate, la diosa lunar que alimenta la juvent ud y la maga que inventa la brujería, además de diosa de los muertos por presidir las apariciones de fantasmas y sortilegios; recordemos que al final se menciona que Consuelo tiene el pelo plateado y abraza a Felipe al pasar la luna ${ }^{15}$.

A las referencias ya indicadas por L. Gyurko, B. Merino y otros a los intertextos de La bruja de J. Michelet en Aura, se pueden agregar algunos relativos a los personajes, especialmente la relación entre la mujer, el Demonio y la casa; la copresencia de la joven y vieja y las dos hechiceras; la asociación entre mujer y plantas, la mención a las plantas equívocas y la descripción de la misa negra. En uno de los relatos del texto de Michelet se cuenta: «la primera palabra era verde. Vio colgada a la puerta de un prendero un vestido verde (color del Príncipe del mundo), vestido viejo que se puso y se encontró joven y deslumbradora» $(52, \mathrm{sic})$. Aura no sólo tiene los ojos verdes - como Consuelo en su juventud-, también viste del mismo color, como las cortinas de terciopelo verde de la casa.

Uno de los primeros rasgos que se destacan de Consuelo es su capacidad de dirigir, sin verlo directamente, los pasos de Felipe cuando ingresa a la casa; una vez allí, el joven advierte la presencia de

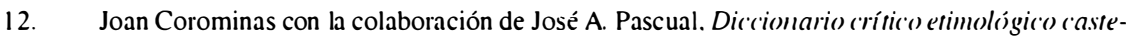
llano e his pánico (III tomo. Madrid: 1980-1986) 333.

13. Muerto en 1823 en Francia. fue comisario del Santo Oficio y autor de la Historia (rírica de la Inquisición, que motivó el cierre de esta institución. Según B. Merino. Michelet habla de un inquisidor francés medieval, cfr. art. cit. 145.

14. Edward A. Roberts y Bárbara Pastor. Dicrionario efimológico indoeuropeo de la lengua española (Madrid: Alianza. 1997) 147: también Villeneuve. 915.

15. Además, los conejos son considerados animales lunares por varias razones. entre ellas, porque duermen de día y brincan de noche. mueren para renacer. Jean Chevalier y Alain Gheerbrant. Diccionario de los símbolos (1969. 5a. edición en español: Barcelona. Herder, 1995) 645-647. 
varias plantas en el pasillo oscuro de la entrada. En La bruja, se advierte que el Demonio y la bruja se dedicaban a la producción de hierbas y poseían el poder de ver a través de los muros. Junto con los verdugos (cirujanos) y los pastores (éstos como veterinarios), las hechiceras conocían la medicina popular, ejercían de parteras y conocían las plantas «equívocas», las Consolantes o Solanáceas: la dulzamara, el beleño, la belladona ${ }^{16}$.

En su amplia explicación sobre las antiguas fiestas de los sábados, Michelet reconstruye la misa negra como un drama en cuatro actos, en el primero de los cuales dominaba la sacerdotisa, llamada la «Vieja». En el segundo acto, la mujer se convierte en el altar ${ }^{17} y$ la hostia y después de la invocación al rayo, ella sacrifica un sapo vestido diciendo estas palabras: « $i A h$, Felipe! Si te tuviera entre mis manos, haría contigo lo mismo» (94). En Aura, durante el segundo encuentro con Felipe leemos: «te of rece la mitad de la oblea (...) caes sobre el cuerpo desnudo de Aura (...) Aura se abrirá como un altar» (49).

Durante la misa negra, el Demonio y la bruja conciben una «hechicerilla», de modo que hay dos mujeres: la madre y esposa del Diablo, y la hija de él ${ }^{18}$. Pero, además, también ocurría una transformación de la vieja en joven después del banquete y la danza: «La vieja entonces ya no era vieja. ¡Milagro de Satanás! Era todavía mujer y deseable, confusamente amada» (93). Consuelo conquistó a Felipe

16. "Con un golpe supremo y decisivo gana a la misma litigante. a la Mujer. a su bella adversaria. la seduce con un argumento. no de palabras sino real. irresistible, poniéndole en la mano el fruto de la ciencia y de la naturaleza». "La gran revolución de las hechiceras» es “la rehabilitación del vientre y de las funciones digestivas". Michelet. 66-67. 73-74 y 77.

17. [A Satanás] «tocaba consagrar a su sicerdotisa (...) la hechicera se entregaba al diablo (...) después. no menos solemnemente, se purificaba y desde entonces era el altar viviente (...) El altar. la hostia aparecía. ¿Qué hostia y que altar? La mujer misma. Con su cuerpo prosternado. con su persona humillada. con el manojo de seda de sus cabellos perdidos en el polvo. se of recia como altar y hostia. y sobre sus desnudos lomos celebraba un demonio diciendo el credo y haciendo el of ertorio", Micheiet. 92-93.

18. «La delicada joya del Diablo, la hechicerilla concebida en la Misa negra, en que desapareciera la grande. vino y ha florecido en gracia y malicia de gato. Esta, al contrario de la otra, es astuta, oblicua, redomada (...) desde la cuna es lúbrica. voluptuosa, concupiscente. Expresará toda su vida cierto momento nocturno, impuro. en que cierto pensamiento que hubiera causado horror de día usó de las libertades del sueiio». Michelet. i 03. 
para terminar de escribir las memorias de su esposo pero también para que lo sustituyera como amante. Michelet explica que era una costumbre medieval que los criados hombres a veces también se convertían en amantes de la dueña de la casa y que la bruja trataba de atraer al hombre joven para hacer maleficios y mantener su juventud ${ }^{19}$. El Demonio, según Michelet, se entiende mejor con las brujas que con los brujos porque, ante el abandono familiar de las mujeres viejas, éstas adoptaban al Demonio como si fueran sus madres o sus novias y él resultaba su amante y maestro. Pero, más que una asociación circunstancial, para el historiador francés la mujer tenía un vínculo esencial con el Demonio: en la naturaleza de la mujer, dice, hay algo que las conduce hacia la magia y la hechicería más que a los hombres; los demonios se hallan en el desierto, el bosque, etc., "pero sobre todo en la casa, en el domicilio particular (...) en lo más íntimo de los hábitos domésticos. La mujer los guarda y esconde hasta en su propio lecho. Allí tienen lo mejor del mundo (mejor aún que el templo) el hogan» (3 y 17 , destacados míos).

\section{La casa-libro}

Entrar a la casa equivale a iniciar la lectura del Libro; éste se abre con facilidad, como las puertas sin cerraduras y despliega las lecturas cruzadas que pueblan el relato. Varios trabajos han señalado la semejanza de Aura con relatos y motivos de la literatura universal ${ }^{20}$. Se puede indicar, además, que en el cuento de hadas «La bella

19. «El joven bello llegará. para que su matrimonio no falte. dará todo lo que ella querrá. hará lo que él querrá». 82-85.

20. De acuerdo con unas declaraciones de Fuentes, por ejemplo, B. Merino ỳ A. Castañón citan los "Papeles de Aspern" de Henry James. Grandes experanzas de Dickens y La reina de la. espadas de Puschkin, tres historias en las que un joven trata de descubrir el secreto de una anciana y termina engañado por una joven: la mujer, aclara Merino. remite tanto a Michelet como a Circe. El segundo autor agrega, además, los poemas de Quevedo y una adaptación cinematográfica del clásico japonés del siglo XVIII de Ugetsu Monogatari Relatos de la lívida lima al terminar la lluria y una traducción italiana de los cuentos japoneses de Togi Boko escritos por Hiosuichi Shoun, en particular el cuento titulado «La cortesana Miyagino», cfr. Blanca Merino, "Fantasía y realidad en Aura de Carlos Fuentes», Literatura mexicana. II-1 (1991) 135-147. "De burlas a veras. Fuentes de Aura». La crónic a de hoy (4 de mayo de 2001). 
durmiente» los personajes se llaman Aurora y Felipe y, como en la novela, se trata del héroe salvador de una joven atrapada en una casa por la maldición de una hada malvada por un tiempo indefinido; en la novela, Felipe imagina a Aura encerrada por la bruja ${ }^{21}$.

La entrada de Felipe en la casa de Consuelo evoca el motivo de la entrada al Averno y la prohibición de la mirada hacia atrás, según el cual la desobediencia de mirar para atrás ocasiona la perdición o la muerte, que a su vez evoca tanto el mito de Orfeo como el relato bíblico de Lot y Sara ${ }^{22}$.

Los ojos verdes de Aura y el hechizo de un joven por una mujer maligna recuerdan «La leyenda de los ojos verdes» de Gustavo Adolfo Bécquer, en la cual sucede lo mismo ${ }^{23}$. La seductora diabólica relacionada con la eterna juventud también aparece en la Odisea: Calipso es 'la que oculta', quien retiene a Ulises con la promesa de la inmortalidad para que narre la historia de Troya. Pero también remite a Circe y, por ésta, a su semejante nórdica Lorelei, mencionada en el texto cuando Felipe observa por última vez las fotografías de Llorente $^{24}$.

21. "te preguntas si la señora no poseerá una fuerza secreta sobre la muchacha. si la muchacha. tu hermosa Aura vestida de verde. no está encerrada contra su v'oluntad en esta casa vieja. sombría. Le sería. sin embargo. tan fácil escapar mientras la anciana dormita en su cuarto oscuro. Y no pasas por alto el camino que se abre en tu imaginación: quizás Aura espera que tú la salves de las cadenas que. por alguna razón oculta. le ha impuesto esta vieja caprichosa y desequilibrada» (36). Sin embargo. cuando ella le propone huir. él ỵa no quiere.

22. "antes de entrar miras por última vez sobre tu hombro" (1.3-14). Las puertas abiertas que Felipe debe franquear refieren al motivo del "fácil ingreso al infierno» o 'facile descensus averno", L. Gyurko. "Identity and the Demonic in two narratives by Fuentes", Revista de Letras (México. 6-21. 1974) 101 .

23. Un hombre ve los ojos verdes en el fondo de la fuente cuyas aguas desembocan en el lago, luego se le aparece la mujer: él la interroga y' al principio ella no le habla, después le promete amor eterno. Finalmente lo hace ahogarse en el lago-abismo con la promesa de amor: él la acepta. como mujer. ángel o demonio.

24. "Y la fotografía de Aura (...) con el paisaje pintado al fondo: el paisaje de Lorelei en el Rin" (58). En ias penas de las orillas del Rın. Loreici atrae a los marineros hacia los despeñaderos seduciéndolos con sus cantos y

dos que. suplantando la razón. conducen al hombre a su ruina». Jean Chevalier y Alain Gheerbrant. Diccionario de ios simbolos (1969. 5a. edición en español: Herder, 1995) 656. Para L. Gyurko. Aura aparenta serbuena pero es un ser destructivo. un demonio: al mismo tiempo es la 'aurora' o luz de la resurrección y Lorelei. o una seductora que ciega a Felipe. una mentirosa. Se asemeja a Felıpe. pues es el fantasma del pasado y él se hace irrealidad. Aura en realidad hipnotiza a todos. Llorente. Felipe y Consuclo. Incluso el conejo es otra forma de Aura. 
Felipe, sin embargo, no es una víctima inocente. Desde el inicio - cuando abandona su investigación por un trabajo que despreciasu actuación revela el moti vo literario de la sed de oro. De acuerdo con éste, se resume la idea del matrimonio de interés como medio de hacer fortuna, para cuya realización se utilizan los servicios de una 'femme d'intrigues'. En medio de la duda inicial, Felipe termina de convencerse cuando Consuelo le of rece más dinero y definitivamente cuando se presenta Aura: anzuelo o especie de «seductora diabólica», se trata de una mujer con un «atractivo irresistible y un carácter mágico-demoníaco, mediante los cuales no sólo vincula consigo eróticamente al hombre sino que también le desvía de sus intereses y tareas superiores, socava su moral y casi siempre le hunde en su desgracia». Para el hombre no siempre es una relación negativa, a veces resulta ambivalente, pues le depara un máximo de satisfacción amorosa ${ }^{25}$. En una dirección similar se ha indicado que Aura es una suerte de autómata, creación efímera de Consuelo, una especie de gólem ${ }^{26}$.

\section{Lector y Amada}

Dijo, con muy buen sentido, que no se podían tomar en serio las confesiones de las hechiceras, porque quien hablaba en ellas era precisamente el padie de la mentira, Michelet.

Así como un lector que continúa libremente la lectura de un libro, Felipe permanece voluntariamente en la casa de Consuelo; una vez allí, ambas mujeres lo dominan: admite la oscuridad en la casa a

25. Elızabeth Frenzel. Diccumario de motives de la literamira universal (1976. edición en espanol: Gredos. i980) 337.

20. Entre otros. B. Merino. para quien Aura es Carlota joven y una creación temporal: «Consuelo es estéril. por lo tanto. no puede esperar recrear el mundo mediante su propia renovación: sólo puede lograr una creación temporal

la magia. Por lo tanto. Aura "c' est l'aura. c'est l'air qui gonfie, et rien de plus» (Michelet. 9899)» destacados míos. 141. E. Paiewonsky considera que Aura es «un artificio. ciciico»: "Aura es criatura mágica tanto por el mecanısmo de su creación como ser experiencia que cifra los tres momentos de la vida de la mujer en tres días", art. cit.. 149-151. 
pesar de que descubre la existencia de la electricidad, Consuelo le va entregando las memorias por partes, Aura determina cuándo y dónde se ven y sus relaciones ocurren en las habitaciones de las mujeres ${ }^{27}$. Pareciera que al personaje le corresponde un papel pasivo, objeto de las órdenes de las mujeres y también del narrador, como se verá luego. Sin embargo, en el curso de su experiencia toma una decisión muy significativa: no sólo abandona su propia investigación sino también la tarea encomendada por Consuelo, convertirse en un escritor con una identidad falsa. Felipe deja de escribir porque no entiende lo que sucede en la casa y sus habitantes.

Cuando finalmente el misterio lo aterroriza, trata de evadirse en el sueño: «Caes en ese sopor, caes hasta el fondo de ese sueño que es la única salida, tu única negativa a la locura. «Está loca, está loca», te repites para adormecerte» (43). Después de la visión de Aura despellejando el chivo, del segundo encuentro con ella y de la sensación de haber engendrado a su propio doble, Felipe deja de pensar «porque existen cosas más fuertes que la imaginación» (51). Luego roba el tercer rollo de las memorias para tratar de hallar en las explicaciones del General sobre Consuelo las claves de lo que sucede con Aura y así, como un lector ingenuo, cree descubrir las explicaciones que despejan sus propias dudas sobre Aura ${ }^{28}$.

Felipe interpreta el texto y las fotos, pero comete un error de lectura, pues pretende ser el General y supone verse a sí mismo y a Aura en las fotografías en el lugar de la pareja Llorente. Aunque él mismo lee en el retrato la fecha - 1876 - y en tinta blanca «la firma, con la misma letra, Consuelo Llorente» (58), sigue sosteniendo que se trata de él y de la joven.

27. Para L. Gyurko. Felipe se caracteriza por su pasividad innata y la derrota, art. cit., passim.

28. El concepto de Lector Ingenuo es de Limberto Eco. En Lector in fabuia (1979, edición en español: Lumen. 1981 ) explica sobre ta competencia intertextual de cada lector, que varía según el grado de conocimientos: entre más rico y variado es el bagaje cultural de un lector. más estará éste en grado de articular diferentes niveles de lectura y, por lo tanto. apreciar más matices y significados en un texto: si el lector. en cambio, es «ingenuo», es decir, con una menor competencia intertextual. tenderá a ver solamente un nivel de lectura más simple. 
En un anhelo semejante o superior al deseo por Aura, Felipe se vuelca a la lectura de los manuscritos al punto que ni ella misma logra convencerlo de huir de la casa. Él busca en los folios algún indicio que explique la.verdad sobre la Amada y cree encontrarlo en la verdad de Llorente sobre Consuelo. Por eso termina creyendo que una es la otra, confunde la realidad con el texto escrito ${ }^{29}$. Es el momento de la confusión, que se consumará en el último encuentro con la mujer que aún cree es Aura. Él interpreta lo leído sobre el pasado como propio de su situación presente, realiza una inversión temporal del texto.

Anteriormente él ya había aceptado sustituir al General, escribir como si fuera el General, aparentar ser otro en la escritura. Se trata, entonces, de una doble o.triple suplantación: en el plano lingüístico, escribir en un idioma distinto al suyo; en el plano textual, pretender ser el Autor de la Autobiografía y, en el plano existencial, proponerse como el general Llorente.

El texto propicia la confusión también en el Lector de Aura, ya que el General y Felipe se oponen y se asemejan en varios aspectos: el primero, viejo, pertenece al pasado y es la pareja de Consuelo; el otro es joven, está en el presente y es pareja de Aura; el General es objeto de la Historia y el muchacho es historiador. Además, el vínculo que establece cada personaje entre su propio espacio y la situación narrativa revela, sobre todo, que ambos, el General-narrador y Felipe-lector, están aprisionados, uno en la casa y otro en los manuscritos.

El desconcierto de Felipe muestra que en su actuación hay un juego entre la libre voluntad y la seducción —amorosa o mágica- - Su conducta es un indicio de confusiones y engaños pero también de traición, que se consuman todos en los signos, verbales e icónicos. Desde el texto y el retrato los seres ficticios del pasado hablan a Felipe. Esas voces fascinan al joven al punto que se atreve a robar y a defraudar

29. También García Núñez interpreta asi el proceder de Felipe: “La voz narrativa también fiuerza la interpretación de la lectura de las memorias por parte del historiador, quien siguiendo a su razon cree percibir en Aura más realidad que en la endeble anciana». art. cit.. 269. destacados mios. 
a su amada. No importa tampoco que esa voz hable en otro idioma: la seducción lo somete, como hizo Consuelo con el General.

Las memorias atrapan a su lector de la misma manera que hizo Aura con el joven huésped. Mujer y texto fascinan porque despiertan el interés absorbente del amante y el lector: el primero cede al otro con el fin de encontrar las claves secretas que lo ayudarán a entender quién es el objeto de su amor, que posee una relación misteriosa con el tiempo ${ }^{30}$. Las respuestas cree hallarlas en la vieja casa que también resguarda a las mujeres. Para llegar hasta los viejos folios que se encuentran custodiados dentro de un viejo arcón, Felipe ha debido adentrarse según una dirección que va desde el exterior moderno hasta el interior antiguo, es decir, un movimiento al mismo tiempo espacial y temporal: el joven ha salido de la parte moderna de la ciudad hacia el centro histórico donde se halla la vieja casa. Una vez allí, penetra al cuarto de Consuelo, donde se halla el baúl que contiene los manuscritos: su lectura es como una espiral que lo conduce a un pasado aun más lejano, a la época de Maximiliano y Carlota ${ }^{3 !}$.

En esta estructura de cajas chinas los manuscritos constituyen a la vez un centro espacial y temporal y la sede del misterio que cree descifrar Felipe al finalizar la lectura del tercer folio. Quien habla desde las viejas páginas, sin embargo, no se dirige al lector, a Felipe, sino a Consuelo. Felipe asiste al diálogo entre otros dos personajes, entre los amantes, es su testigo. Y de esta manera la situación dialógica de los folios se convierte en un espejo del texto que estamos leyendo, el que cuenta la historia de Felipe.

30. Para Eduardo Thomas Duble. haly un proceso de rencuentro con la Historia. que se traduce en una efectiva regresión en la qui el pasado. del que és portadora ía anciana Consuelo, se apodera del presente. representado por el joven historiador. Sin embargo, «nı las hechicerías de aqueIla ni la juventud de Felıpe. son suticientes para revitalizar a una situación de encierro estéril. en la que el pasado. convociado por el presente. termina por apoderarse de este último hasta identificarse con él». Dublé. art. cit.

31. Hay que apuntar que en la actual ciudad de México. en la calle Donceles. en el centro histórico se hallan las librerías de segunda mano. 


\section{El narrador y su espejo}

El narrador de Aura comunica los actos y los pensamientos de Felipe en un aparente diálogo con el personaje. Al hacerlo, le ordena hacer lo que el otro va ejecutando en un presente casi inmediato (entre acto y narración) ${ }^{32}$. Reeve propuso que la interlocución del narrador con el personaje implica una doble orientación de su voz — hacia Felipe y hacia el Lector-, lo cual genera una ambigüedad específica al dirigirse a ambos al mismo tiempo. Se podría agregar también que el empleo del TÚ mantiene al narrador fuera de los acontecimientos: mientras un narrador homodiegético se identifica con algún personaje, el tipo de narrador de Aura hace más bien un movimiento contrario: marca una presencia cuya identidad se mantiene oculta y, al mismo tiempo, con ese gesto introduce al Lector en el mundo narrado.

El diálogo entre el narrador y Felipe distingue un YO (hablante) y un TÚ (actor). Esta relación se duplica en la historia: el General como narrador de su vida y Felipe como lector de la autobiografía. Ambas relaciones hacen equivalentes a Felipe y el Lector y los convierte en dobles. Si se distinguen, además, los diferentes planos que convoca todo texto - la historia, la situación comunicativa, la situación narrativa y la situación escritura/lectura-, estas equivalencias se podrían organizar de la siguiente manera:

32. Para García Núñez. además de algunos pasajes descriptivos, la voz narrativa emite sobre todo «enunciados perlocutivos o performatıvos», lo cual reviste el discurso de «un tono imperatıvo. categórico, el deber ser», art. cit.. 266-267. 


\begin{tabular}{l|c|c|c|c}
\hline \multicolumn{2}{l|}{ COMUNICACIÓN } & YO & TÚ & $\begin{array}{r}\text { ELLO } \\
\text { (referente) }\end{array}$ \\
\hline \multirow{2}{*}{ HISTORIA } & acontecimientos & $?$ & Felipe & Aura \\
\cline { 2 - 5 } & manuscritos & General & Felipe & $\begin{array}{r}\text { biografía: } \\
\text { Consuelo }\end{array}$ \\
\cline { 2 - 5 } & aviso periódico & Consuelo & Felipe & $\begin{array}{r}\text { ausente, } \\
\text { el buscado }\end{array}$ \\
\hline $\begin{array}{l}\text { SITUACIÓN NARRATIVA } \\
\text { SITUACIÓN DE }\end{array}$ & narrador & lector & [historia] \\
\hline \begin{tabular}{l} 
ESCRITURA/LECTURA \\
\hline
\end{tabular} & autor & lector & texto \\
\hline
\end{tabular}

Todas las casillas pueden llenarse, excepto la que refiere la identidad del hablante en el plano de los acontecimientos de la historia. Sin embargo, esta voz puede caracterizarse por varios rasgos. En primer lugar, desde la primera palabra del texto hasta la última, la referencia al acontecer del persunaje se anticipa a la acción y esto se logra mediante el uso de mandatos con verbos en tiempos presente y futuro. Así, se constituye un tejido narrativo muy peculiar, pues en el fondo el narrador no refiere acontecimientos sucedidos.

Una primera consecuencia de lo anterior es que la situación narrativa se constituye de manera que resulta similar a la existente entre Felipe y las dos mujeres: el narrador se dirige a su actor en una relación a la vez dialógica y dominante. En segundo lugar, la voz del narrador produce un efecto inquietante: su identidad parece esconderse tras las órdenes que imparte al obediente personaje masculino.

$\mathrm{Y}$ tiene que estar escondido porque la voz que habla encubierta pertenece a una presencia cuyo nombre no se puede decir sin invocarlo. 
Múltiples son sus nombres, larga es su historia y variados sus disfraces, pero su función principal parece ser siempre una, seducir. Como el narrador, Satanás es una presencia invisible pero siempre está, en el mundo y en el relato; para hacerse presente, para atrapar al joven lector, necesita el cuerpo y la voz de la bruja. De nuevo Michelet: «la alegría más grande del Diablo, este gran lógico, es proponer al doctor, mediante la voz de la falsa vieja, argumentos embarazosos, preguntas insidiosas» (94). Entonces, la voz que habla con Felipe y también con el lector, es la de la anciana, sí, aunque en realidad ella se la presta a su maestro, a aquel que le permite conservar la presencia de la juventud y cautivarlo, con maleficios, con su doble o su gólem.

Si bien por pocos días, somos los testigos del retorno del viejo General en el cuerpo del joven historiador o, lo que es más siniestro aún, él no era quien había creído ser durante veintisiete años, era en realidad la reencarnación de un hombre muerto muchos años atrás. Cuando Felipe cree ser el General y cree ver a Aura en las fotos de Consuelo, ha terminado dentro de los textos, se ha sumergido dentro de ellos, éstos se lo han tragado.

El Demonio se ha relacionado con la eterna juventud no sólo porque a veces aparece figurado como un joven que nunca envejece sino también porque tiene el poder de concederla, recordemos nada más a Fausto y Dorian Gray. Por eso hacia el final Felipe dice que no le sirve el reloj, «objeto inservible que mide falsamente un tiempo acordado a la vanidad humana, esas manecillas que marcan tediosamente las largas horas inventadas para engañar el verdadero tiempo» (59). Los objetos que marcan el devenir temporal ya no son útiles porque en los libros y los retratos el tiempo se paraliza, allí los personajes no envejecen, producto del acto de magia de la escritura: como la bruja, el Autor puede conjurar el paso de los años. Una vez inmovilizados por los signos del texto, los personajes permanecerán atados a una edad inalterable en los folios amarillos. Entrar al Libro es entrar a la morada del Demonio; leer, permanecer en la casa, significa ser consumido por aquello que se lee y transformarse en la materia leída. 
Ahora se entiende mejor por qué el narrador de Aura sólo podía narrar de esa forma: no puede hablar en primera persona porque Felipe no puede contar lo sucedido en el pasado, ya que probablemente no tiene vida más allá de esos tres días; tampoco puede hacerlo en tercera porque, al ser un ente sin autonomía, creación maléfica, especie de títere, tiene que actuar bajo la dirección de otro, el narrador, quien le indica lo que debe hacer y pensar.

Felipe permanecerá en el Libro hasta que aparezca un nuevo lector que vuelva a recorrer el mismo camino, atraído por la misma mujer que lo cautivará con el hechizo de las páginas de las memorias. Manejada por una bruja, Aura es una especie de señuelo, cuya juventud significa que el Libro no ha sido leído, es desconocido, que está allí mientras no se han terminado las páginas por leer. Ella es aquello que el Lector piensa que obtendrá al final de las páginas, la respuesta a la interrogante que la misma obra le planteó apenas puso un pie en la casa, es decir, apenas empezó a leer. Conforme Felipe progresa en la lectura de los tres folios, Aura va envejeciendo y, finalizada la lectura, cuando el libro se acaba, ella tiene que desaparecer. 'Aura', se lee en el Diccionario del Diablo, es una «atmósfera inmaterial difícilmente definible, que emana de ciertos seres con fuerte personalidad (...) que a menudo han pasado por un influjo mágico» ${ }^{33}$.

En Instinto de Inez ciertos detalles recuerdan a Aura: hacia el final de la historia, el músico contempla una fotografía de la amada joven, y también los amantes se encuentran tres veces, en tres lugares distintos, para representar juntos el Fausto de Berlioz. La última vez, el director logra el triunfo de su vida; ella, sin embargo, no participa, ha desaparecido de su existencia. Antes de esto, ya se ha transparentado esta igualdad entre la mujer y el libro, cuando el hombre reflexiona lo siguiente: "Quizás el cuerpo de Inez era como la ópera misma. Hace visible lo que la ausencia del cuerpo - el que recordamos y el que deseamos - nos entrega visiblemente» ${ }^{34}$.

33. Dicrionario del Diablo. 67.

34. Carlos Fuentes, Instinto de Inez (México: Alfaguara, 2001) 82. 
Ambos libros, Aura e Instinto de Inez, parecen dialogar a través de las décadas transcurridas, el segundo para responder a la promesa del primero. Recordemos que en Aura Consuelo promete: «Volverá, Felipe, la traeremos juntos», y en la última novela la vieja criada del director le asegura: «No volverá ya. Usted va a morir». Esa advertencia parece dirigida al lector que, al terminar la obra cree que llegar al final del texto equivale a resolver el misterio, sea éste o no la misma amada. La primera novela encierra una propuesta diversa: con el triunfo final de la bruja, los brazos de ésta retendrán al joven, el Libro finalmente ha consumido a su Lector. De forma periódica se renovará la magia que atrapará al incauto, pues el tiempo transcurre en perpetuos giros, es un laberinto circular que engulle hacia adentro, como en un perpetuo calendario lunar que se repite hasta el infinito. 